\title{
Environmental Management Systems in Municipal Waste Management, On the Example of a Selected Waste Disposal Plant
}

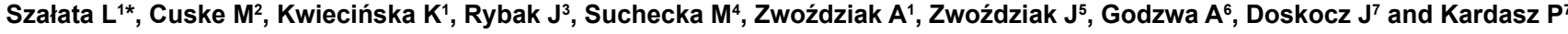 \\ ${ }^{1}$ Department Ekologistyki and Environmental Risk Management, Department of Environmental Engineering, Technical University of Wroclaw, Pl. Grunwald 9, 50-377, \\ Wroclaw, Poland \\ ${ }^{2}$ Institute of Soil Sciences and Environmental Protection, University of Environmental and Life Sciences, Norwida 25, 50-375, Wroclaw, Poland \\ ${ }^{3}$ Institute of Biology and Ecology, Department of Environmental Engineering, Technical University of Wroclaw, Grunwald 9, 50-377, Wroclaw, Poland \\ ${ }^{4}$ Municipal Office of Wroclaw, Department of Environment and Agriculture , ul. Bogusławski 8, 1050-031, Wroclaw, Poland \\ 5 Institute of Meteorology and Water Management, National Research Institute, ul. Podleśna 6101-673, Warszawa, Poland \\ ${ }^{6}$ Eco Pro Natura, Waste Management Plant in Lower Ścinawka, Poland \\ ${ }^{7}$ Cluster Development Research and Innovation - Pilsudski 74/322 Wroclaw, Poland
}

\begin{abstract}
The article presents the environmental management system of the Waste Disposal Plant in Scinawka Dolna, based on the legal and administrative procedures and the use of best practices and best available techniques, in order to minimize the object's potential negative environmental impact. Environmental impact assessment and environmental management systems were analyzed, under Polish and European legal regulations.
\end{abstract}

Keywords: Municipal waste; Plant; Waste disposal; Bio-drying; Biostabilization

\section{Introduction}

Waste production is an integral part of human activity and its management can be a huge problem. Polish Environmental Law imposes a number of specific requirements, aimed to prevent the occurrence of damage to the environment during this process. The necessity of waste management arises from the need to save resources, limit the increase of areas occupied by waste disposal and processing installations, as well as from the need to reduce their environmental impact [1].

The subject of waste management has recently gained interest, not only from the economy and society, but also the scientific community. Municipal waste production is an element of municipal economy, which includes all sources of waste, produced in urban agglomerations. In large production systems, food and other components are partly processed into waste and the chemical energy, contained in fuels, is converted for energy purposes. During the use of this mass - energy stream, waste are being produced, which cannot be fully exploited, so a certain part of the waste stream must be disposed.

Therefore, waste management sets the requirements and challenges to the waste disposal and processing technologies, to prevent them from posing a threat to the environment. Waste management in Poland should include all activities that aim to its integration. The introduction of regional solutions system, helped to manage the waste stream more effectively and provide delivery to the landfills and waste processing plants, with the volume and weight of waste reduced by $50 \%$.

An integrated waste management will allow Poland meet legal requirements imposed by the European Union, in achieving current recycling levels and municipal waste processing methods.

According to these assumptions, regional waste disposal plants, that support the voivodeship areas, have become a basic element of waste management in Poland.

Regional waste disposal plants should be equipped in waste recovery and processing installations, which enable the highest possible performance, through the use of waste recovery and processing methods, meeting the requirements of BAT (Best Available Techniques) and taking into account environmental protection.
The implementation of an integrated municipal waste management idea, taking into account the sustainable development principles, requires a rational approach to environmental management and the use of tools, such as environmental management systems, national legal regulations and European conventions and directives. An additional form of control of the environmental protection instruments, are Environmental Impact Assessment (EIA) Reports, which serve as a basic tool of environmental protection management in the development processes, in line with the sustainable development principles [2-4].

This article presents a description of environmental management systems of the Waste Disposal Plant in Scinawka Dolna, Poland. Effectiveness and performance efficiency of the existing environmental management system were analyzed, under applicable law. Additionally, SWOT analysis of current waste disposal technology, in relation to waste disposal technology with the use of plastic sleeves (which is a commonly used, inexpensive method of waste processing) was performed.

\section{Legal Regulations in the Environmental Impact Assessment}

Environmental impact assessment (EIA) provides key information, relating to potential environmental impact of an installation and defines potential environmental impact on each component of the environment in an optimal way.

As a consequence of the legal order of proceedings, a range of

"Corresponding author: Szałata L, Department Ekologistyki and Environmenta Risk Management, Department of Environmental Engineering, Technical University of Wroclaw, Grunwald 9. 50-377 Wroclaw, Poland, Tel: +48713202600; E-mail: lukasz.szalata@pwr.edu.pl

Received May 18, 2016; Accepted July 30, 2016; Published August 08, 2016

Citation: Szałata L, Cuske M, Kwiecińska K, Rybak J, Suchecka M, et al. (2016) Environmental Management Systems in Municipal Waste Management, On the Example of a Selected Waste Disposal Plant. J Pet Environ Biotechnol 7: 294. doi: 10.4172/2157-7463.1000294

Copyright: @ 2016 Szałata L, et al. This is an open-access article distributed under the terms of the Creative Commons Attribution License, which permits unrestricted use, distribution, and reproduction in any medium, provided the original author and source are credited. 
compensation measures are to be adopted, in case of the occurrence of damage to the environment.

The EIA Reports has been mandatory in Poland for several years, but since the Act of 9 November 2000 on access to information on the environment and its protection and on the assessment of environmental impact (Journal of Laws of 2000, No. 109, item 1157) has been adopted, i.e. from 2001, legal regulations in accordance with European Union and international conventions legislation are being applied [5].

This act transposes into the Polish legislation the EU requirements, in the field of so-called horizontal legislation, i.e. Council Directive 85/337/EEC of 27 June 1985 on the assessment of the effects of certain public and private projects on the environment and Council Directive 90/313/EEC of 7 June 1990 on the freedom of access to information on the environment [5].

The basic legal act that regulates the environmental impact assessment in Poland is the Act of 3 October 2008 on providing information on the environment and environmental protection, public participation in environmental protection and on environmental impact assessment (Journal of Laws of 2008, No. 199, item 1227), which specifies the obligations under, i.e., Directive 2001/42/EC of the European Parliament and of the Council of 27 June 2001 on the assessment of the effects of certain plans and programmes on the environment, Directive 2011/92/EU of the European Parliament and of the Council on the assessment of the effects of certain public and private projects on the environment, the Council Directive 92/43/EEC of 21 May 1992 on the conservation of natural habitats and of wild fauna and flora and Council Directive 79/409/EEC of 2 April 1979 on the conservation of wild birds.

Both Council Directive 90/313/EEC and the Aarhus Convention guarantee everyone the right to the information on the environment and environmental protection, held by public authorities [6].

By the term "everyone", it is understood, that the access to information cannot be dependent on nationality or domicile and doesn't need an explanation of the matter of interest.

The administration bodies and local governments are obliged to provide such information, as well as other organization units, if they're established to handle public tasks, concerning the environment and its protection issues.

Environmental Protection Law Act of 27 April 2001 also regulates the access to information on the environment. The act defines the principles of environmental protection and the conditions of use of natural resources, taking into account the requirements of sustainable development and particularly determining:

a. Conditions for the protection of environmental resources;

b. Conditions for the introduction of substances or energy into the environment;

c. Costs related to the use of environmental resources;

d. Sharing information on the environment and its protection;

e. Public participation in the proceedings on the protection of the environment;

f. Duties of the administrative bodies;

g. Responsibility and sanctions.

In addition, detailed executive and implementing acts have been issued complementary to the directives described above.

\section{Characteristic of Waste Disposal Plant in Scinawka Dolna, Poland}

Waste Disposal Plant is located in Scinawka Dolna, Poland, in the Klodzko district. The plant is located on the site of a former aggregate mine (sand and gravel mine). As a result of the exploitation of raw materials, the area has been geotechnically deformed, followed by the formation of pit surrounded by steep slopes, which set the plant's current borders.

The exploitation of raw materials in the analyzed area caused a complete destruction and transformation of soils. In the area of the plant, there are mainly clay and loam grounds, which seal the bottom of the landfill, slopes separating the landfill and soils, mainly isolated by the impermeable layers.

On the basis of noise measurements and data obtained from the investor, the modeling of the acoustic impact of the plant on the adjacent areas has been performed [7]. There were no exceedances of the limit values for the sound levels on facades of residential buildings located in the vicinity of the analyzed object.

The emission of pollutants from the landfill did not exceed the values defined in the Regulation of the Minister of Environment of 26 January 2010 on reference values for certain substances in the air (Journal of Laws of 2010, No 16, item 87) [8]

Numerous studies on invertebrate animals have also been conducted during the growing season, with the use of various research methods. During the study only common species were observed, not covered by any kind of protection. Also during the inspection on the presence of protected species, no traces of protected amphibians, reptiles and mammals existence were observed.

In the area of the plant, vegetation is poorly developed, mainly due to the nature of works carried out previously in this area. However, some ruderal species have been observed, such as coltsfoot, some grass species and few others. Also the presence of shrubby forms of willows and small trees indicates the onset of secondary succession and probably the formation of synanthropy community.

Therefore, monitoring activities have been recommended as well as application of measures minimizing the environmental impact of the plant.

The plant is not located in the area protected under the Nature Protection Act of 16 April 2004 (Journal of Laws of 2004, No. 92, item 880). Furthermore, in the area surrounding the plant, Stolowe Mountains National Park and its buffer zone is located, as well as Natura 2000 nature protection area "Stolowe Mountains PLH020004".

\section{Municipal waste disposal technology}

Mechanical - biological treatment of mixed municipal waste and green and biological waste processing installation, located in the Waste Disposal Plant in Scinawka Dolna, consists of the following sections (Figure 1):

a. Reception of waste.

b. Discharge and homogenization of waste.

c. Biological section-biodrying, biostabilization and composting, consisting of 26 reactors.

d. Mechanical segregation of waste. 


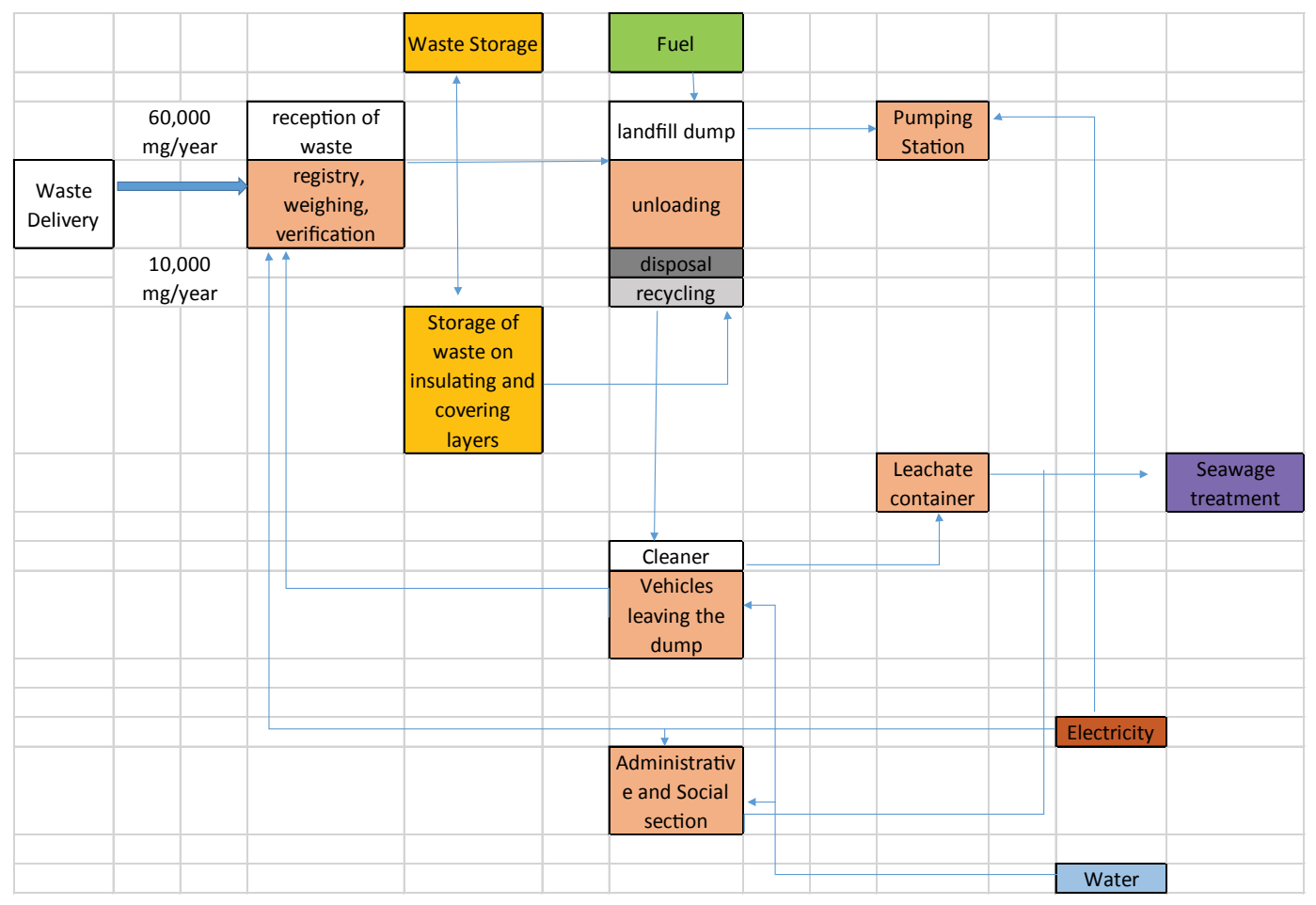

Figure 1: The main line technology diagram.

\section{e. Waste storage section.}

f. Administrative and social section.

g. Parking lots, maneuvering areas and internal roads.

The biological treatment is the treatment of waste in concrete bioreactors, under the airtight membranes, under controlled conditions of airflow and temperature, which provides full control of leachates. The leachates occurring during the biodrying process are collected separately without mixing with the rainwater and can be reused if necesarry. Also the odour emission control is provided due to the use of the semi-permeable membranes, which has been proved by the researchers from the Institute for Modelling Hydraulic and Environmental Systems, University of Stuttgart and Hohenheim. The results confirm that this technology not only meets the current legal requirements but may also fit to future regulations. The technology of this installation, if operated correctly, allows the reduction of odour emissions by $97 \%$.

The system also provides the control of pathogenes, which also has been proved by the researchers from the University of Stuttgart and Hohenheim (Institute of Phytomedicine and Institute of Environmental and Animal Hygiene). The research results confirm that the bio-drying technology is able to produce an uncontaminated and hygienic material. All microorganisms are being destroyed during bio-drying process (99\% reduction of microorganisms), what limits their negative impact on the workers of the plant and the environment.

The landfill, together with necessary infrastructure, meets the requirements of the Regulation of the Minister of Environment of 30 April 2013, on detailed requirements for the location, construction and operation of landfills. The investor has provided the required geological barrier on the slopes and on the bottom of the landfill. The barrier is made of HDPE foil with a thickness of $2 \mathrm{~mm}$. Landfill gas is purified and combusted. The landfill is encircled by trenches, aimed to reduce the rainwater flow.

The SWOT analysis carried out for the Waste Disposal Plant in Scinawka Dolna, indicated that despite the high cost of the technology, it is optimal both in ecological and economic terms. In the nearest future, requirements imposed to mmechanical - biological treatment plants will change - i.e. they will be based on the requirements of BAT (best available techniques).

Technology of waste disposal used in the Waste Disposal Plant in Scinawka Dolna meets the requirements of BAT, which is a great advantage of this system - it is guaranteed, that it will meet the legal requirements, even after the amendment of the Regulation of the Minister of Environment on detailed requirements for the location, construction and operation of landfills.

In order to minimize possible negative environmental impact, solutions aimed to protect the environment have been implemented, such as:

a. Monitoring of the state of equipment, with special attention to the tightness of the fuel and hydraulic systems and in case of oil or fuel leakage, collection of contaminated soil masses and delivery to the place, where contamination will be neutralized;

b. Immediate neutralization of any leaks that may occur during the process, with the use of appropriate methods and sorbents;

c. avoiding soil erosion on slopes, with an introduction of appropriate grass species;

d. Surrounding the landfill with a shelterbelt consisting of trees and shrubs, in order to minimize inconveniences and risks resulting from odour and dust emission from the landfill, spreading waste by the wind, noise and traffic, animal interactions, aerosol and fire formation; 
e. The use of degassing wells, in order to minimize the impact of landfill gas on the air;

\section{f. Storm water drainage system improvement;}

g. the control of composition, quality and quantity of discharged wastewater, which should be consistent with the parameters specified in the water permit;

\section{h. Quality control of the final material reaching the landfill.}

Specific requirements, relating to the operation of mechanicalbiological mixed municipal waste treatment installations, as well as waste generated in these processes, are given in the the Regulation of the Minister of Environment of 11 September 2012, on the mechanicalbiological treatment of mixed municipal waste (Journal of Laws of 2012, item 1052). It's the most important regulation regarding this type of installation, under which requirements for regional installations in the Regional Waste Management Plan are established.

\section{SWOT analysis for waste processing technology used in the plant}

The SWOT analysis is one of the most popular and comprehensive heuristic methods, used to analyze the organization's environment (which is an area of research) and interior. Internal analysis aims to identify and assess both tangible and intangible factors, which may favor the development of the organization or impede its function in the future. SWOT analysis is the algorithm of the strategic analysis process, a proposal of systematic and comprehensive assessment of external and internal factors that determine the current condition and potential development of the organization, company or program [9-11].

The scope of factors that affect the subject of SWOT analysis is very wide. There are both external and internal factors relating to the environmental management as well as negative and positive factors. The essence of the SWOT analysis is a correct identification of following categories of factors $[12,13]$

a. External positive (opportunities) - key factors, that allow to maintain the current position or to develop;

b. External negative (threats) - key factors, which are an obstacle to the maintenance of current position or its development;

c. The threats have a negative impact especially on the maintenance of current position, as well as development perspective. Their correct identification is the basis for the development of a proper strategy.

d. Internal positive (strengths) - identification of strengths results from a thorough knowledge of the analyzed subject. The deeper the knowledge is, the more effective is the analysis. Strengths depend on the type of the analyzed item. Almost every time, strengths depend on resources and object analysis qualification;

e. Internal negative (weaknesses) - identification of weaknesses is similar to the identification of strengths of the analyzed subject and is a result of thorough knowledge of the analyzed subject. Almost every time, weaknesses are the result of the lack of resources and lack of object analysis qualification

On the basis of SWOT analysis, it is possible to make a reliable comparison of the waste disposal technology used in the Waste Disposal Plant in Scinawka Dolna and the waste disposal technology with the use of plastic sleeves. The analysis showed the advantages and disadvantages of these technologies in terms of environmental impact and economics but also in terms of current legal regulations.
Comparing the environmental impact of these technologies, the technology used in Waste Disposal Plant in Scinawka Dolna has many advantages - there are specifically designed sanitary installations, designed to protect the environment. They prevent leachates from infiltration into the surface water, groundwater and soils as well as minimize the emission of pollutants into the atmosphere.

The technology proposed by the BIO-COM company is equipped with sleeves made of durable materials; however, in the case of any leaks in the sleeves, the emission of pollutants may occur, which may affect the flora and fauna in the area of an installation. In terms of the economic aspects, the big advantage of the plastic sleeves technology used by BIO-COM, is a low price.

Comparing all aspects - ecological and economical, despite the large advantage of the BIO-COM technology (low price), the technology used in the Waste Disposal Plant in Scinawka Dolna is optimal in terms of these aspects.

The last important factor that needs to be considered is whether these two technologies meet requirements, imposed by EU Directives, Polish regulations and the assumptions of the National and Regional Waste Management Plan. At this moment, both technologies meet requirements of the Regulation of the Minister of Environment of 30 April 2013, on detailed requirements for the location, construction and operation of landfills. However, in the nearest future, the amendment of this regulation is about to be introduced and the requirements imposed to mechanical - biological treatment plants will change - i.e. they will be based on the requirements of BAT (best available techniques).

In this case, the BIO-COM technology will not meet the requirements described above. The stabilization process that runs in plastic sleeves, do not fulfill the criteria of a required tightness of the bioreactor. In the planned amendment to the Regulation of the Minister of Environment of 30 April 2013, on detailed requirements for the location, construction and operation of landfills, an article is to be added, defining the obligation of the total tightness of the bioreactor, which disqualifies the plastic sleeves technology at the initial stage.

Moreover, most of such systems, lack the closed air circulation system, allowing adjusting the conditions of aeration during the process. Additionally, due to the lack of leachates drainage system, anaerobic conditions may occur during the process. However, these two features can be adapted to the requirements.

In contrast to plastic sleeves technology, the technology used in the Waste Disposal Plant in Scinawka Dolna, due to the closed nature of the waste disposal installation, appropriate security systems, excellent leachates drainage and gas purification systems, meet all the requirements of both the Regulation of the Minister of Environment of 30 April 2013, on detailed requirements for the location, construction and operation of landfills and the best available techniques (BAT).

\section{Conclusion}

Implementation of system activities is a matter of great importance in terms of mixed municipal waste stream disposal. Experiments and studies conducted in recent years, indicated that there is no universal method of municipal waste disposal and processing. There is also no method that would provide a total elimination of municipal waste, what results in the need of waste storage.

The optimal solution is a comprehensive, individually designed for each urban agglomeration, municipal waste disposal system, taking into account regional, socio-economic and environmental conditions. 
Citation: Szałata L, Cuske M, Kwiecińska K, Rybak J, Suchecka M, et al. (2016) Environmental Management Systems in Municipal Waste Management, On the Example of a Selected Waste Disposal Plant. J Pet Environ Biotechnol 7: 294. doi: 10.4172/2157-7463.1000294

Page 5 of 5

Technological progress indicates that the best available techniques become competitive, not only in terms of ecological factors, but also economic, what is extremely important for the condition of the environment.

The use of SWOT analysis, aiming to optimize waste management processes gives a chance for constant optimization of pro-environmental activities, with respect to the principles of sustainable development.

\section{References}

1. Kulczycka J, Pietrzyk-Sokulska E (2009) Evaluation of waste management in Poland. Meeri Pan Publishing, Kraków.

2. Deszka M, Dworakowska M, Gos M, Wąsowicz M (2014) Management of environmental resources. Fundamentals of environmental economy. Rzeszów Publishing, Rzeszów University of Technology Warsaw.

3. Kryński A, Kramer M, Caekelbergh A (2013) Integrated environmental management - System relationships between politics, law, management and technology. Wolters Kluwer Business Publishing, Warsaw.

4. Nowak M, Dabrowski B (2013) The law on access to information on the environment and its protection, public participation and impact assessment on the environment - Practical comment, Economics Books Online, Warsaw.

5. Kyoto Protocol (2002) Directive 2002/358/EC of 25 April, on the approval of the Kyoto Protocol on climate change and the joint fulfillment of commitments there under.

6. Access to Information Convention (1998) On public participation in decisionmaking and access to justice in environmental matters, the Convention signed on 25 June, in Aarhus.

7. Szałata $Ł$, Zwoździak J (2011) SWOT analysis as a key tool in environmental management. Yearbook of Environmental Protection.

8. Cuske M, Szałata L (2014) Modelling the spread of pollutants in the air on the example of the planned accommodation landfill Zielonogórskie pp: 34.

9. Jasinski Z (2007) Fundamentals of operational management. Publishing Economics, Cracow.

10. Obój K (2007) Strategy organizations-in the search for sustainable competitive advantage. (2ndedn) revised, Polish Economic Publishing House, Warsaw.

11. Zwoździak J (2007) SWOT heuristic analytical technique. National Foresight Programme Poland 2020 - Technologies for environmental protection, Rzeszow.

12. Przegląd komunalny (2007) Abrys.

13. Szałata $Ł$, Cuske M, Godzwa A (2014) Comparison of models of propagation of acoustic waves on the example of the functioning of the Department of Waste Management in the Lower Ścinawka, Notebooks Zielonogórskie. 